\title{
Polysaccharide lyases from gellan-producing Sphingomonas spp.
}

\author{
lan W. Sutherland and Lynn Kennedy
}

Author for correspondence: Ian W. Sutherland. Tel: + 44131650 5331. Fax: + 441316505392.
e-mail: I. W.Sutherland@ed.ac.uk

Institute of Cell and Molecular Biology, Edinburgh University, Mayfield Road, Edinburgh EH9 3JH, UK

\begin{abstract}
A number of Sphingomonas strains capable of synthesizing the bacterial exopolysaccharide gellan and related polymers were shown to possess constitutive gellanase activity. In each case, the degradation of deacylated gellan was due to extracellular, eliminase-type enzymes (lyases) which cleave the sequence ... $\beta$-D-glucosyl 1,4- $\beta$-D-glucuronosyl... in the tetrasaccharide repeat unit of the substrate polysaccharides. Deacetylated rhamsan was an alternative substrate but there was little or no action against most other polysaccharides with similar structures. Slight differences were found between the specificities of the lyases from different strains. Activities of gellan lyase preparations were generally low. As well as the extracellular 'gellanase' activity, all the bacteria possessed varying amounts of $\beta$-D-glucosidase and $\beta$-Dglucuronidase activities apparently located in the periplasm. The products from deacylated gellan and the chemically deacylated form of polysaccharide S194 (rhamsan gum), which is effectively a gentiobiosylated form of gellan, closely resembled those recently obtained by the authors from other, gellandegrading, non-gellan-producing bacteria. The enzymes had negligible activity against the natural, acylated gellan and rhamsan polysaccharides from bacteria now designated as strains of Sphingomonas.
\end{abstract}

Keywords: gellanases, gellan lyases, polysaccharides, polysaccharases

\section{INTRODUCTION}

Gellan is marketed as Gelrite, the chemically deacylated polysaccharide gelling agent obtained from bacteria originally designated as Auromonas (Pseudomonas) elodea, but now termed Sphingomonas strains (Pollock, 1993). The polymer is one of eight closely related bacterial products which share much of their backbone structure but differ in the nature and location of their side-chains and in the presence or absence of acyl groups (Jansson et al., 1983, 1985, 1986a, b; Cairns et al., 1991; Stankowski \& Zeller, 1992). In its native form, gellan is composed of linear tetrasaccharide repeating units in which $O$-acetyl and Lglyceryl residues are attached to the D-glucosyl residue adjacent to D-glucuronic acid (Fig. 1) (Jansson et al., 1983; Kuo et al., 1986). The structurally related polysaccharides from bacteria now also considered by Pollock (1993) to be Sphingomonas strains possess similar linear structures in which there is at least an identical -(D-glucose-D-glucuronic acid-D-glucose)- trisaccharide sequence with the same linkages and anomeric configurations as gellan.

Abbreviations: EPS, exopolysaccharide; TBA, thiobarbituric acid.
Several of these polymers are acylated, form highly viscous aqueous solutions and show high thermal stability but do not normally form gels. The gelling agent 'gellan' is produced on deacylation with mild alkali and is marketed as Gelrite; it forms brittle gels in the presence of cations such as $\mathrm{Mg}^{2+}$ (Baird et al., 1983).

Polysaccharide-degrading enzymes either effect hydrolytic cleavage of the polymers (glycanohydrolases) or act as polysaccharide lyases through a $\beta$-eliminative mechanism (Linhardt et al., 1986; Sutherland, 1987, 1990, 1995). Polysaccharide lyases have been obtained from bacteria, fungi and bacteriophages; a few have been found in the same microbial species which produce the polysaccharide substrates. Schmedding et al. (1987) briefly described a lyase-type enzyme acting on gellan, but gave no information about the specificity of the enzyme. Mikolajczak et al. (1994) reported an enzyme activity, designated 'sphinganase', from a Bacillus sp. The material acted in undetermined fashion, possibly as an endoglycanase, on welan, to a lesser extent on gellan but not on rhamsan (Fig. 1) We recently reported the isolation in pure culture of several bacteria growing on deacylated gellan as sole carbon and energy source and providing a 
(a) Gellan gum

-3-B-D-Glcp-(1 $\rightarrow 4)-\beta-D-G l c p A-(1 \rightarrow 4)-\beta-D-G l c p-(1 \rightarrow 4)-\alpha-L-R h a p-(1-$

(b) Welan gum ( $\$ 130)$

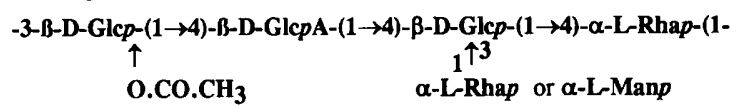

(c) Rhamsan gum (S194)

-3-B-D-Glcp-(1 $\rightarrow 4)-\beta-D-G l c p A-(1 \rightarrow 4)-\beta$-D-Glep-(1 $\rightarrow 4)-\alpha-L-R h a p-(1-$ $1^{\uparrow 6}$

B-D-Glcp $(1 \rightarrow 0) \alpha-D-G l c p$

(d) 5657

-3- $\beta$-D-Glcp-(1 $\rightarrow 4)-\beta-D-G I c p A-(1 \rightarrow 4)-\beta-D-G l c p-(1 \rightarrow 4)-\alpha-L-R h a p-(1-$ $1^{\uparrow 3}$

$\alpha-\mathbf{L}-\mathbf{R h a p}(1 \rightarrow 4) \alpha-\mathbf{L}-\mathbf{R h a p}$

(e) 588

-3-B-D-Glcp-(1 $\rightarrow 4)-\beta-D-G l c p A-(1 \rightarrow 4)-\beta-D-G l c p-(1 \rightarrow 4)-\alpha-L-R h a p-(1-$ ${ }_{1} \uparrow^{3}$ or $\alpha-L-M a n p$ a-L-Rhap

(f) $\mathrm{S} 198$

-3-B-D-Glcp-(1 $\rightarrow 4)$-B-D-GlcpA-(1 $\rightarrow 4)-\beta-D-G l c p-(1 \rightarrow 4)-\alpha-L-R h a p-(1-$ $1^{\uparrow 3}$ $\alpha-$ L-Rhap

(g) NW11

-3-B-D-Glcp-(1 $\rightarrow 4)-\beta-D-G l c p A-(1 \rightarrow 4)-\beta-D-G l c p-(1 \rightarrow 4)-\alpha-L-M a n p-(1-$

Fig. 1. Structures of gellan and related polysaccharides.

source of novel degradative enzymes (gellanases or gellan lyases) (Kennedy \& Sutherland, 1994). These lyases yielded oligosaccharide fragments with a non-reducing terminal unsaturated uronic acid; the bacteria producing them also produced intracellular glycosidases. Following the observation by ourselves (A. M. de Souza \& I. W. Sutherland, unpublished results) and others (e.g. Martins \& Sá-Correia, 1994) that several cultures of Sphingomonas spp. showed reduction in the yield of exopolysaccharide (EPS) on prolonged incubation, we now report the presence of a polysaccharide lyase activity in some of the Sphingomonas spp. which synthesize gellan and related polymers. Although preparations were active against deacylated substrates they generally failed to show significant degradation of the native polysaccharide from which gellan is prepared.

\section{METHODS}

Bacterial culture and enzyme isolation. The bacteria used in this study were EPS-producing strains now designated as Sphingomonas spp.: ATCC 31461, 31961, 31554 and 31555; and NCIMB 11942. Although all these strains produce polysaccharides with some structural similarity to gellan, strain NCIMB 11942 differed from the others in apparently producing a typical lipopolysaccharide as opposed to sphingolipid. In some cases, spontaneous polysaccharide-negative mutants were isolated in our laboratory. Strain Mj216 (a spontaneous EPS derivative of ATCC 31461) was kindly supplied by Dr I. SáCorreia, Instituto Tecnico, Lisbon, Portugal. Bacteria were cultured on glucose-free semi-synthetic medium consisting of a salts base supplemented with $0 \cdot 1 \%(\mathrm{w} / \mathrm{v})$ yeast extract and $0 \cdot 1 \%(\mathrm{w} / \mathrm{v})$ casein hydrolysate as nitrogen source (Sutherland \& Wilkinson, 1965) and solidified with $0.75 \%(\mathrm{w} / \mathrm{v})$ gellan. Alternatively, a similar medium containing $1 \%(\mathrm{w} / \mathrm{v})$ glucose and solidified with $1.2 \%(\mathrm{w} / \mathrm{v})$ agar was used for routine culture. Those cultures which produced significant depressions around colonies on gellan medium, indicative of gellanase production, were repeatedly subcultured onto the same medium, then onto yeast extract agar plates. Finally, gellanase activity in the pure cultures was confirmed by further plating on gellan medium plates incubated at $30^{\circ} \mathrm{C}$.

The gellanase-producing strains were then used to prepare extracellular enzymes by growing the bacteria in the semisynthetic medium containing $0.05 \%$ gellan or in the same medium with glucose as carbon substrate. Cultures $(900 \mathrm{ml}$ aliquots in 21 Erlenmeyer flasks) were grown for $5-6 \mathrm{~d}$ at $30^{\circ} \mathrm{C}$ with shaking at about 200 r.p.m. Bacteria were removed by centrifugation at $30000 \mathrm{~g}$ for $30 \mathrm{~min}$. The clear supernatant fluid was concentrated by tangential-flow filtration (Millipore Minitan), recentrifuged and dialysed exhaustively against

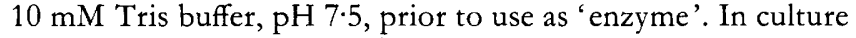
supernatants which contained relatively large amounts of EPS, the polymer was removed by tangential-flow filtration as described by Sutherland \& Macdonald (1986), although this also caused some loss of enzyme activity. Ultrasonic lysates of the bacterial cells provided sources of intracellular glycosidases. The lysates were ultracentrifuged at $110000 \mathrm{~g}$ for $60 \mathrm{~min}$, dialysed in the cold against $10 \mathrm{mM}$ Tris buffer, $\mathrm{pH} 7 \cdot 5$, and concentrated if necessary by dialysis against polyethylene glycol (molecular mass $6 \mathrm{kDa}$ ), then stored at $-40^{\circ} \mathrm{C}$.

Analytical procedures. Enzyme assays for lyase activity used the thiobarbituric acid (TBA) assay procedure of Weissbach $\&$ Hurwitz (1958). Assays for $\beta$-D-glucosidase, $\beta$-D-glucuronidase and other glycosidases were performed using nitrophenyl sugar derivatives as substrates (Sigma). Viscosity changes due to enzyme action were measured at $30^{\circ} \mathrm{C}$ using a Brookfield LV'TD instrument. Monosaccharides were identified in acid hydrolysates of the polysaccharides $\left(0.25 \mathrm{M} \mathrm{H}_{2} \mathrm{SO}_{4}\right.$ for $16 \mathrm{~h}$ at $100^{\circ} \mathrm{C}$ ) or of the oligosaccharide products of enzyme treatment, by descending paper chromatography using butan-1ol/pyridine/water $(6: 4: 3$, by vol.) as mobile phase, then quantified by HPLC as indicated by Kennedy \& Sutherland (1987). Oligosaccharides were also compared by paper electrophoresis in pyridine/acetic acid/water (1:10:100, by vol., $\mathrm{pH}$ $3.5)$ at $180 \mathrm{~mA}$ for $2 \mathrm{~h}$.

Gellan was purchased from Schweizerhall. Native and deacetylated rhamsan gum were kindly provided by Dr S. Zeller of Kelco, Aero Drive, San Diego, CA, USA. Other related polysaccharides were either prepared in our laboratory or kindly donated by Dr J. Baird (Kelco). The commercial polysaccharides, except gellan and welan, were dissolved in distilled water, ultracentrifuged to remove particulate material, purified by extensive dialysis and lyophilized before use. Deacetylation of the polysaccharides was performed by heating $1 \%(\mathrm{w} / \mathrm{v})$ solutions in $0.05 \mathrm{M} \mathrm{NaOH}$ at $100{ }^{\circ} \mathrm{C}$ for $15 \mathrm{~min}$, neutralization with $0.1 \mathrm{M} \mathrm{HCl}$, dialysis against distilled water and lyophilization.

Preliminary experiments indicated that interaction of concentrated culture supernatants with gellan increased the reducing material present and released material reacting in the TBA test. There was also increase in $A_{235}$. Optimal enzyme activity was observed at $\mathrm{pH} 7 \cdot 0-7 \cdot 5$ when tested against gellan and over a 
broader $\mathrm{pH}$ range, $4 \cdot 5-8 \cdot 0$, when tested against deacetylated rhamsan. The optimum temperatures were $35-40{ }^{\circ} \mathrm{C}$.

\section{RESULTS}

\section{Gellan degradation by bacteria}

Concentrated supernatants of all five wild-type Spbingomonas strains, and the $\mathrm{EPS}^{-}$mutant Mj216, showed some degradation of gellan but did not show detectable degradation of cellulose, xanthan, sodium pectate, agarose or other polysaccharides tested using reducing sugar assays and chromatographic examination for the production of oligosaccharides or other breakdown products. Cell lysates of glucose- or gellan-grown cells of the ATCC strains did not show any degradation of gellan, deacylated rhamsan or related polysaccharides but were strongly active against the $\beta$-D-glucoside and the $\beta$-D-glucuronide but not against other nitrophenyl glycoside substrates tested, including the $\alpha$-L-rhamnoside. The lysate of strain NCIMB 11942 failed to degrade gellan but differed in that it possessed strong $\beta$-D-glucosidase activity and only weak activity against the nitrophenyl- $\beta$-D-glucuronide. On further testing for release of reducing sugar or TBAreactive material, concentrated culture supernatants from all the bacterial strains grown in the presence or absence of gellan showed activity against acyl-free gellan and deacetylated rhamsan.

\section{Enzyme isolation}

Supernatant fluid from gellan-grown cultures was recovered after centrifugation and concentrated by tangentialflow filtration (Waters Millipore Minitan; $10 \mathrm{kDa}$ molecular mass cut-off). After extensive dialysis, further concentration was achieved using polyethylene glycol (molecular mass $6 \mathrm{kDa}$ ). The presence of gellan lyase activity in the concentrated fluid was confirmed using the TBA method. The relatively low activities of the enzymes, and the presence of EPS in some preparations, caused some problems in the attempted partial purification of the proteins. The concentrated supernatants from strains Mi216 and NCIMB 11942 were dialysed against $10 \mathrm{mM}$ Tris buffer $(\mathrm{pH} 7 \cdot 0)$ and subjected to chromatography on columns $(22 \times 1 \mathrm{~cm}$ or $85 \times 2.5 \mathrm{~cm})$ of the strong anionexchanger Q Sepharose FF (Pharmacia) using a stepwise gradient of $\mathrm{NaCl}$ in Tris buffer at a flow rate of $17.6 \mathrm{ml}$ $\mathrm{h}^{-1}$. After elution of unbound material with three column volumes of Tris buffer, in a typical purification, $68 \%$ of the lyase activity eluted at $0.4 \mathrm{M} \mathrm{NaCl}$. The semi-purified enzymes from wild-type strains and from Mj216 and the EPS $^{-}$mutant of NCIMB 11942 now showed much simpler profiles on PAGE and were used for further studies.

\section{Enzyme specificity and activity}

The concentrated and partially purified enzymes from all the bacteria behaved similarly but not identically; polysaccharide lyase activities were frequently very low. All preparations appeared to be highly specific, acting on

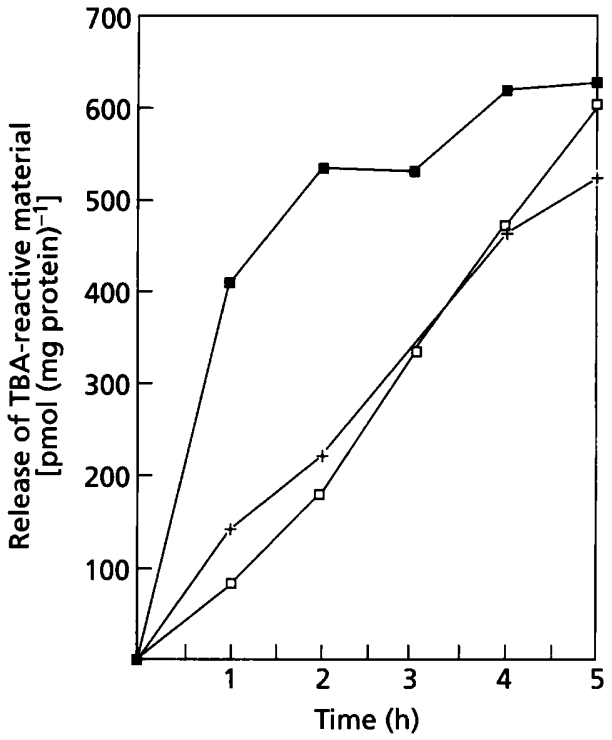

Fig. 2. Action of gellan lyase preparations from Sphingomonas strains Mj216 and NCIMB 11942 on deacylated gellan and

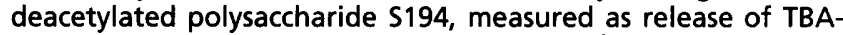
reactive material. Substrate $\left(5 \mathrm{ml}, 1 \mathrm{mg} \mathrm{ml}^{-1}\right)$ was mixed with $5 \mathrm{ml} 10 \mathrm{mM}$ Tris, $\mathrm{pH} 7.0$, and $5 \mu \mathrm{l}$ enzyme $(1.25$ or $1.97 \mathrm{mg}$ protein $\mathrm{ml}^{-1}$ ) and incubated at $30^{\circ} \mathrm{C}$. Aliquots $(500 \mu \mathrm{l})$ were removed and boiled for $5 \mathrm{~min}$. The TBA assay was then performed on triplicate $100 \mu \mathrm{l}$ samples. $\mathbf{a}$, Enzyme from strain NCIMB 11942 acting on deacylated gellan;,$+ \square$, enzyme from strain Mj216 acting on deacylated gellan (+) and deacetylated S194 ( $\square)$

deacylated gellan and the deacylated polysaccharide from strain ATCC 31961 (Kelco polymer S194, 'rhamsan') (Fig. 2, Table 1). They generally lacked activity on other, structurally similar polysaccharides in the series, whether in the native acetylated or the deacetylated form. Nor were they active on the original acylated polysaccharide from which gellan is derived. There was linear release of material reacting in the TBA assay from either gellan or deacylated polysaccharide over a $10-12 \mathrm{~h}$ period. Thereafter, TBA-reacting products continued to be formed but at a lower rate. An exception was seen in the Mj216 preparation, which did show some activity against the batch of native S657 polysaccharide tested, although surprisingly it was inactive against the corresponding deacetylated material. The two strains used for most of the experiments were chosen because of their apparently higher activity and also because one (Mj216) was a mutant derived from a strain typical of Spbingomonas spp. in lacking lipopolysaccharide (ATCC 31461), while the other (NCIB 11942) was atypical and apparently possessed LPS (H. Weitz \& I. W. Sutherland, unpublished results). Activity of the enzymes was slightly $(10 \%)$ enhanced by the addition of $5 \mathrm{mM} \mathrm{Ca}^{2+}$. Higher concentrations were inhibitory. Other cations at various concentrations failed to cause any stimulation of enzyme activities.

Incubation of enzyme preparations from $\mathrm{Mj} 216$ or NCIMB 11942 with aqueous solutions of deacylated gellan or the chemically deacetylated polysaccharide S194 
Table 1. Relative activities of enzymes from Sphingomonas strains against gellan and related polysaccharide substrates

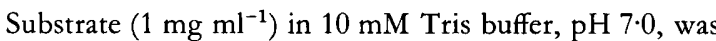
incubated with enzyme and samples were taken at 0 and $3 \mathrm{~h}$ for the TBA reaction.

\begin{tabular}{|lcc|}
\hline \multirow{2}{*}{ Substrate } & \multicolumn{2}{c|}{ Enzyme source: } \\
\cline { 2 - 3 } & Strain & NCIMB \\
& Mj216 & $\mathbf{1 1 9 4 2}$ \\
\hline Gellan & 100 & 100 \\
Native gellan & 0 & 0 \\
S194 (rhamsan) & $2 \cdot 4$ & 0 \\
S194 DAC (deacetylated rhamsan) & $46 \cdot 9$ & $40 \cdot 3$ \\
S194 DAC (deacetylated rhamsan)* & $40 \cdot 2$ & $37 \cdot 1$ \\
S88 & $5 \cdot 2$ & 0 \\
S88 DAC (deacetylated S88) & $4 \cdot 7$ & $0 \cdot 5$ \\
S130 (welan) & $2 \cdot 7$ & $7 \cdot 0$ \\
S130 DAC (deacetylated welan) & $2 \cdot 4$ & 0 \\
S198 & $0 \cdot 6$ & 0 \\
S198 DAC (deacetylated S198) & 0 & 0 \\
S657 & $10 \cdot 7$ & 0 \\
S657 DAC (deacetylated S657) & 0 & $1 \cdot 1$ \\
11942 & 0 & 0 \\
11942 DAC (deacetylated 11942) & 0 & 0 \\
\hline
\end{tabular}

* Sample prepared by Dr S. Zeller at Kelco.

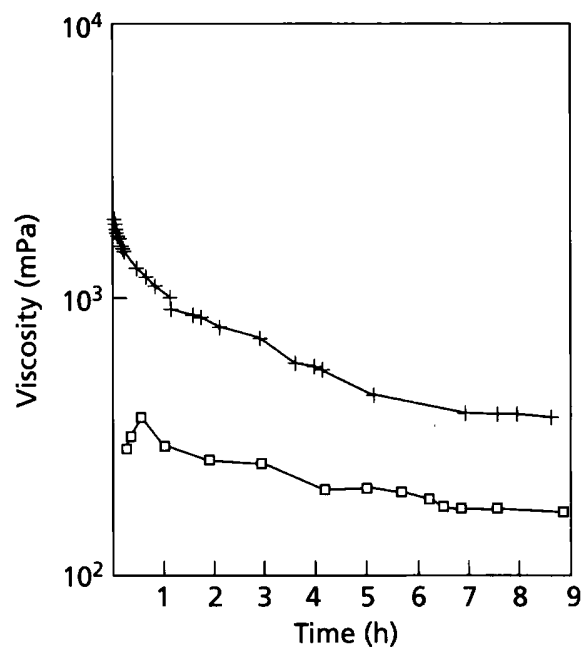

Fig. 3. Effect of gellan lyase preparations from Sphingomonas sp. NCIMB 11942 on solution viscosity. The polysaccharide $(2 \mathrm{ml})$ at a concentration of $5 \mathrm{mg} \mathrm{ml}^{-1}$ for deacetylated $\$ 194$ or $2.5 \mathrm{mg}$ $\mathrm{ml}^{-1}$ for deacylated gellan, was mixed with $50 \mu$ l enzyme $(1.25$ or $1.97 \mathrm{mg}$ protein $\mathrm{ml}^{-1}$ ) and the viscosity was determined over a period of time in the Brookfield viscometer at $30^{\circ} \mathrm{C}$, using spindle speed 0.3. +, Deacylated gellan; $\square$, deacetylated S194.

(rhamsan gum) as substrates indicated loss in viscosity with time (Fig. 3). These results were mirrored by an increase with time in the release of reducing sugar and characteristic oligosaccharides from both substrates as

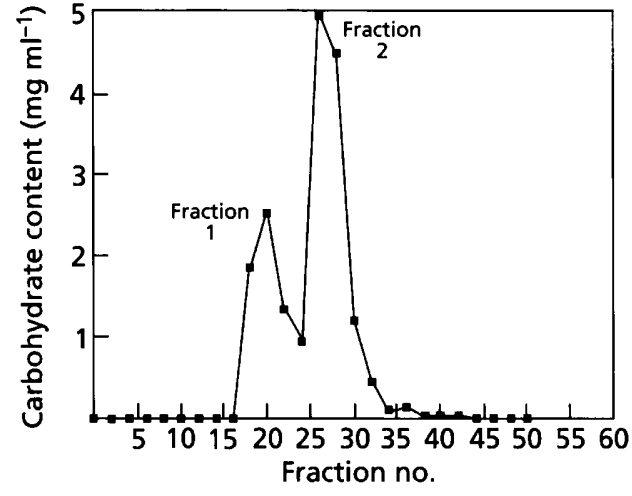

Fig. 4. Chromatography on Biogel P2 of diffusible products from digests of deacylated gellan using enzyme from strain Mj216. The pooled diffusible material from incubation at $30^{\circ} \mathrm{C}$ for $25 \mathrm{~h}$ was evaporated to dryness under reduced pressure at $50{ }^{\circ} \mathrm{C}$, redissolved in $1 \mathrm{ml}$ deionized water, centrifuged and applied to the Biogel P2 column. The column was eluted with water as indicated in Methods and fractions collected at $12.5 \mathrm{~min}$ intervals. Samples $(10-100 \mu \mathrm{l})$ were tested for carbohydrate content using the phenol/sulphuric acid assay.

followed by paper chromatography. All incubation mixtures contained some residual non-diffusible, polymeric material even after extensive enzyme treatment. A problem was encountered during attempts to use enzyme preparations from the other strains due to the presence of EPS and its contribution to the measurable viscosity values.

As well as the extracellular polysaccharide lyases, the bacterial strains under examination possessed intracellular $\beta$-D-glucosidase and $\beta$-D-glucuronidase activities. The products of exhaustive enzyme degradation of deacylated gellan appeared to be oligosaccharides with an unsaturated uronic acid at the non-reducing terminal. Analogous products were obtained from the deacetylated polysaccharide S194, but glucose was additionally detected, presumably due to digestion of part of the side-chain residues by $\beta$-glucosidase. Paper chromatography or HPLC of digests of either substrate failed to reveal any free rhamnose. The low molecular mass products recovered after dialysis of enzyme digests of deacylated gellan could be separated by gel permeation chromatography on Biogel P2 into two major fractions (Fig. 4). On paper chromatography of fraction 1 , there was a major slow-migrating product $\left(R_{\text {Glc }} 0 \cdot 07\right)$, which was possibly the repeat unit tetrasaccharide into which a double bond has been introduced at the non-reducing terminal uronic acid. On paper electrophoresis, this oligosaccharide had a similar mobility to other tetrasaccharides containing a single uronic acid residue. Smaller amounts of other slower-moving material may represent oligomers of this tetrasaccharide. Fraction 2 contained material of $R_{\mathrm{Glc}} 0.55$ which appeared to contain equimolar amounts of $\mathrm{D}$ glucose, L-rhamnose and unsaturated uronic acid, but has not yet been fully characterized. The profile on Biogel P2 of the products of enzyme digestion of deacetylated S194 resembled that from deacylated gellan, but paper chroma- 
tography of the material showed it to be considerably more complex, especially among the slower-moving products, and lacking the fastest-moving oligosaccharide. The oligosaccharides were all TBA-positive when eluted from preparative paper chromatograms. The chromatographic and electrophoretic mobilities of many of the products were identical to those of the oligosaccharides reported in our earlier study on gellan lyases (Kennedy \& Sutherland, 1994). Further characterization of the oligosaccharide fragments from both substrates is in progress. Analysis of acid hydrolysates of the undigested limit material from either polymer revealed no differences from the initial substrates other than the presence of small amounts of TBA-reactive material.

\section{DISCUSSION}

Gram-negative bacteria capable of degrading deacylated gellan through the action of eliminase-type enzymes (lyases) have recently been isolated by enrichment culture (Kennedy \& Sutherland, 1994). The enzymes differ from those associated with a bacterium recently reported by Mikolajczak et al. (1994) to degrade welan gum and to a lesser extent gellan. We now report the presence of polysaccharide lyases in several of the Sphingomonas spp. which are used in the commercial production of gellan and polysaccharides of related structure. Intracellular $\beta$-Dglucosidase and $\beta$-D-glucuronidase activities were also noted but $\alpha$-L-rhamnosidase activity was absent, in contrast to the gellan-degrading bacteria studied earlier by us (Kennedy \& Sutherland, 1994). The specificity of the enzymes from Sphingomonas spp. degrading deacylated gellan resembles that of the enzymes from the bacteria studied earlier, but the Sphingomonas enzymes show higher activity against gellan than against deacetylated thamsan. Chromatographic analysis of the products also reveals close similarities. One surprising result was the failure of the enzymes to hydrolyse the EPS from strain NCIMB 11942 if, as suggested by Lobas et al. (1994), it is very similar to gellan in chemical structure as well as in physical properties. However, only the composition of this polysaccharide was reported and no structural details have been determined (Anson et al., 1987); this polymer may well show sufficient structural differences to explain the lack of enzyme action.

The enzymes described here correspond to some other polysaccharide lyases, including many of those active on alginates, which have been shown to be strongly inhibited by the presence of the $O$-acetyl or other acyl groups present on the polymeric substrates (Davidson et al., 1977; Kennedy et al., 1992). O-Acetyl groups can greatly affect the ordered structure adopted by some bacterial polysaccharides in solution (e.g. Sutherland, 1994), but it is surprising that a relatively small substituent on the polysaccharides should affect susceptibility to enzyme action. This is especially true when one considers that the enzymes in our study degraded rhamsan gum, in which there is a gentibiosyl side-chain attached to the glucose residue distal to the uronic acid (Fig. 1). The ordered structure resulting from this substituent is clearly still available for enzyme attack, provided all acyl groups have been removed. However, despite their similar structures, welan and S657 are resistant. Polymers in which substituent side-chains are on the glucosyl residue attached to the reducing terminus of the uronic acid were not substrates for the enzymes under study; this may therefore indicate that the binding or cleavage site extended to the glucose residues on either side of the glucuronic acid. Crescenzi et al. (1987) observed that in the conformation adopted in aqueous solutions, the short side-chains of $\mathrm{L}$ mannose or L-rhamnose mask the uronic acid residues through hydrogen bonding. Lee \& Chandrasekaran (1991) used X-ray and computer modelling of gellan and three structurally related polysaccharides to conclude that although all have double-helical conformations, the sidechains shielded the carboxylate groups to varying degrees. The shielding was extensive in welan and S-657 polysaccharides, but low in rhamsan. Complete removal of the side-chains would be required to leave completely exposed carboxylate groups, as is found in gellan. This might allow the enzyme to cleave at its recognition site, which in the polysaccharides rhamsan and gellan, is unsubstituted.

The gellan lyases are newly identified enzymes in a series of polysaccharide lyases isolated mainly from bacteria and bacteriophages, but also from other sources. Such enzymes include alginases (alginate lyases), pectate lyase, xanthan lyase, heparinase, chondroitinase, and a number acting on various other bacterial EPSs. These enzymes all cleave the main chains of uronic-acid-containing polysaccharide substrates in which there is a $1,4-\alpha$ - or $\beta$ glycosyl residue linked to the uronic acid, except for xanthan lyase, which attacks the side-chains (Sutherland, 1995). In non-polysaccharide-producing bacterial species, the presence of various polysaccharide lyases enables the bacteria synthesizing them to convert various polysaccharides and the corresponding monosaccharide products to 2-keto-3-deoxy-aldonoates which can then be metabolized further to pyruvate and triose phosphate (e.g. Preiss \& Ashwell, 1963).

Although Pseudomonas aeruginosa and other alginatesynthesizing Pseudomonas spp. possess alginate lyase activity, none can utilize alginate as sole carbon and energy source. A similar situation has now been demonstrated in bacteria of the genus Sphingomonas synthesizing gellan and structurally related polysaccharides. This raises the question of a possible role for EPS-degrading enzymes in bacterial strains which excrete EPS. Are these lyases therefore, essentially connected with polysaccharide synthesis and excretion? If so, this is not confined to the production of polysaccharide lyases. Rhizobium spp. capable of synthesizing the EPS succinoglycan contain a succinoglycan depolymerase gene among the genes essential for polymer biosynthesis (Glucksman et al., 1993) and 1,4- $\beta$-D-endoglucanases (CM-cellulases) have recently been reported in two species of cellulose-synthesizing bacteria, in close association with the polysaccharide biosynthetic genes (Standal et al., 1994; Mattysse et al., 1995). On the other hand, studies on EPS-synthesizing Escherichia coli and related bacteria have apparently totally 
failed to reveal the presence of enzymes degrading the EPSs which they synthesize (K. Jann, I. S. Roberts and C. Whitfield, personal communications). Surprisingly, no enzyme activity was detected in the cytoplasmic contents obtained from bacterial lysates. This might suggest that the role of the enzymes is in cleavage of polysaccharide chains at the surface of the cell rather than in a periplasmic or intracellular location. In such a location, the enzymes might release excess polysaccharide or cleave material covalently linked to other surface macromolecules.

\section{REFERENCES}

Anson, A., Fisher, P. J., Kennedy, A. F. D. \& Sutherland, I. W. (1987). A bacterium yielding a polysaccharide with unusual properties. J Appl Bacteriol 62, 147-150.

Baird, J. K., Sandford, P. A. \& Cottrel, I. W. (1983). Industrial applications of some new microbial polysaccharides. BioTecbnology 1, 778-783.

Cairns, P., Miles, M. J. \& Morris, V. J. (1991). X-ray fibre diffraction studies of members of the gellan family of polysaccharides. Carbobydr Polym 14, 367-372.

Crescenzi, V., Dentini, M. \& Dea, I. C. M. (1987). The influence of side-chains on the dilute solution properties of three structurally related, bacterial anionic polysaccharides. Carbobydr Res 160, 283-302.

Davidson, I. W., Sutherland, I. W. \& Lawson, C. J. (1977). Localization of $O$-acetyl groups of bacterial alginate. J Gen Microbiol 98 , 603-606.

Glucksmann, M. A., Reuber, T. L. \& Walker, G. C. (1993). Genes needed for the modification, polymerization, export and processing of succinoglycan by Rbizobium meliloti: a model for succinoglycan biosynthesis. J Bacteriol 175, 7045-7055.

Jansson, P.-E., Lindberg, B. \& Sandford, P. A. (1983). Structural studies of gellan gum, an extracellular polysaccharide elaborated by Pseudomonas elodea. Carbobydr Res 124, 135-139.

Jansson, P.-E., Lindberg, B., Widmalm, G. \& Sandford, P. A. (1985). Structural studies of an extracellular polysaccharide (S130) elaborated by Alcaligenes ATCC 3155. Carbobydr Res 139, 217-223.

Jansson, P.-E., Kumar, N. S. \& Lindberg, B. (1986a). Structural studies of a polysaccharide (S-88) elaborated by Pseudomonas ATCC 31554. Carbobydr Res 156, 165-172.

Jansson, P.-E., Lindberg, B., Lindberg, J., Mackawa, E. \& Sandford, P. A. (1986b). Structural studies of a polysaccharide (S194) elaborated by Alcaligenes ATCC 31961. Carbobydr Res 156, 157-163.

Kennedy, A. F. D. \& Sutherland, I. W. (1987). Analysis of bacterial exopolysaccharides. Biotechnol Appl Biochem 9, 12-19.

Kennedy, L. \& Sutherland, I. W. (1994). Gellan lyases-novel polysaccharide lyases. Microbiology 140, 3007-3013.

Kennedy, L., McDowell, K. \& Sutherland, I. W. (1992). Alginases from Azotobacter species. J Gen Microbiol 138, 2465-2471.

Kuo, M.-S., Mort, A. J. \& Dell, A. (1986). Identification and location of L-glycerate, an unusual acyl substituent in gellan gum. Carbobydr Res 156, 173-187.
Lee, E. J. \& Chandrasekaran, R. (1991). X-ray and computer modelling studies on gellan-related polymers: molecular structures of welan, S-657, and thamsan. Carbobydr Res 214, 11-24.

Linhardt, R. J., Galliher, P. M. \& Cooney, C. L. (1986). Polysaccharide lyases. Appl Biochem Biotechnol 12, 135-176.

Lobas, D., Nimtz, M., Wray, V., Schumpe, A., Proppe, C. \& Deckwer, W.-D. (1994). Structure and physical properties of the extracellular polysaccharide PS-P4 produced by Sphingomonas paucimobilis P4 (DSM6418). Carbobydr Res 251, 303-318.

Martins, L. O. \& SáCorreia, I. (1994). Temperature profiles of gellan gum synthesis and activities of biosynthetic enzymes. Biotechnol Appl Biochem 20, 385-395.

Mattysse, A. G., White, S. \& Lightfoot, R. (1995). Genes required for cellulose synthesis in Agrobacterium tumefaciens. J Bacteriol 177, 1069-1075.

Mikolajczak, M. J., Thorne, L., Pollock, T. J. \& Armentrout, R. W. (1994). Sphinganase, a new endoglycanase that cleaves specific members of the gellan family of polysaccharides. Appl Environ Microbiol 60, 402-407.

Pollock, T. J. (1993). Gellan-related polysaccharides and the genus Sphingomonas. J Gen Microbiol 139, 1939-1945.

Preiss, J \& Ashwell, G. (1963). Polygalacturonic acid metabolism in bacteria. II. Formation and metabolism of 3-deoxy-D-glycero-2,5hexodiulosonic acid. J Biol Chem 238, 1577-1583.

Schmedding, D. J. M., van den Dool, R. T. M. \& Kerkenaar, A. (1987). Characterisation of a Gelrite depolymerizing enzyme. Abstract B47, Proceedings of Eurocarb IV, Darmstadt.

Standal, R., Iverson, T.-G., Coucheron, D. H., Fjærvik, E., Blatny, J. M. \& Valla, S. (1994). A new gene required for cellulose production and a gene encoding cellulolytic activity in Acetobacter xylinum are colocalized with the bcs operon. J Bacteriol 176, 665-672.

Stankowski, J. D. \& Zeller, S. G. (1992). Location of a second Oacetyl group in welan by the reductive cleavage method. Carbobydr Res 224, 337-341.

Sutherland, I. W. (1987). Xanthan lyases - novel enzymes found in various bacterial species. J Gen Microbiol 133, 3129-3134.

Sutherland, I. W. (1990). Biotechnology of Microbial Exopolysaccharides. Cambridge: Cambridge University Press.

Sutherland, I. W. (1994). Structure-function relationships in microbial exopolysaccharides. Biotechnol Adv 12, 393-448.

Sutherland, I. W. (1995). Polysaccharide lyases. FEMS Microbiol Rev 12, 323-347.

Sutherland I. W. \& Macdonald, R. M. (1986). Extracellular enzyme isolation and purification from exopolysaccharide-producing bacteria. J Microbiol Meth 6, 27-31.

Sutheriand, I. W. \& Wilkinson, J. F. (1965). Depolymerases for bacterial exopolysaccharides obtained from phage-infected bacteria. $J$ Gen Microbiol 39, 373-383.

Weissbach, A. \& Hurwitz, J. (1958). The formation of 2-keto-3deoxyheptonic acid in extracts of Escherichia coli. J Biol Chem 234, 705-709.

Received 3 August 1995; revised 25 November 1995; accepted 5 December 1995. 